\title{
A systematic review of McKittrick-Wheelock syndrome
}

\author{
MR Orchard ${ }^{1}$, J Hooper ${ }^{2}$, JA Wright ${ }^{3}$, K McCarthy ${ }^{4}$ \\ ${ }^{1}$ Gloucestershire Hospitals NHS Foundation Trust, UK \\ ${ }^{2}$ University Hospitals Bristol NHS Foundation Trust, UK \\ ${ }^{3}$ The Chinese University of Hong Kong, China \\ ${ }^{4}$ North Bristol NHS Trust, UK
}

\section{ABSTRACT}

INTRODUCTION McKittrick-Wheelock syndrome describes the condition of extreme electrolyte and fluid depletion caused by large distal colorectal tumours, usually the benign villous adenoma. Patients generally present critically unwell with severe hyponatraemia, hypokalaemia and/or acute kidney injury.

METHODS A structured literature review was undertaken to discover what is known about this condition, which is almost universally described as rare. Important features of the syndrome were identified, including common presenting symptoms, blood results, tumour location and size.

FINDINGS Our literature search identified 257 cases reported across all languages. The most remarkable features were the long duration of symptoms (median 24 months) and the significant electrolyte derangements (median sodium of $122 \mathrm{mmol} / \mathrm{l}$ and median potassium of $2.7 \mathrm{mmol} / \mathrm{l}$ at initial presentation).

Five key recommendations are made to improve diagnosis, including aggressive fluid resuscitation to match rectal losses and surgical intervention on the index admission. The advantages and disadvantages of different treatment options are discussed, including minimally invasive alternatives to traditional resectional surgery.

CONCLUSIONS McKittrick-Wheelock syndrome describes a normally benign condition that can cause patients to become critically unwell and so it behoves all clinicians to be aware of it. By publishing recommendations based on a comprehensive literature review, we aim to improve diagnosis and management of this life threatening condition.

\section{KEYWORDS}

Rectal tumour - Water-electrolyte imbalance

Accepted 10 September 2018

CORRESPONDENCE TO

Melanie Orchard, E: morchard@doctors.org.uk

The phenomenon of extreme electrolyte depletion and acute kidney injury secondary to a rectal villous adenoma has long been described. Prior to the eponymisation of the syndrome by McKittrick and Wheelock in $1954,{ }^{1}$ there was a case report in 1940 of a 'pre-renal uraemia due to papilloma of the rectum'. Surgeons and physicians alike have continued to be fascinated by this usually benign condition causing severe and sometimes fatal electrolyte disturbances.

The published literature has mostly been limited to case reports of one or two patients at a time, almost universally referring to the condition as rare. There have been six literature reviews since 1961. The most recent of these in $2016^{3}$ identified 35 published cases but was limited to a PubMed search and English language reports only. The largest review was in $2014^{4}$ and reported 132 cases published in the medical literature.
Despite the reported rarity of this condition, as far back as 1959 Roy and Ellis reported 2 cases in 18 months, and suggested that the condition 'may be not so much rare as overlooked'. ${ }^{5}$ In 2010 Caliskan et al reported four cases in a single hospital over a two-year period. ${ }^{6}$ The largest case series came from Georgeac et al, who presented 14 patients with electrolyte disturbances secondary to rectosigmoid tumours. ${ }^{7}$

Estimating the prevalence of this condition is difficult. Villous adenomas account for $5 \%$ of colonic adenomas ${ }^{8,9}$ and it has been suggested that $3 \%$ of villous adenomas exhibit secretory activity. ${ }^{10,11}$ Nicholson and Naughler propose that these tumours exhibit a spectrum of secretory activity rather than a binary divide, and it is likely that only the more extreme cases are identified. ${ }^{4}$ Multiple case reports also highlight that tubulovillous adenomas and adenocarcinomas can exhibit the same phenomenon. 
Historically, there have often been long delays to diagnosis and definitive treatment of McKittrick-Wheelock syndrome. The aim of this systematic review was to collate information from the published literature to try to optimise our management of these patients.

\section{Methods}

A systematic literature review was undertaken in accordance with PRISMA (Preferred Reporting Items for Systematic Reviews and Meta-Analyses) guidelines. ${ }^{12}$ The databases employed for the search were Embase ${ }^{\mathrm{TM}}$, MEDLINE $^{\circledR}$, PubMed, CINAHL ${ }^{\circledR}$ (Cumulative Index to Nursing and Allied Health Literature), AMED (Allied and Complementary Medicine Database), BNI (British Nursing Index), HBE (Health Business Elite), HMIC (Healthcare Management Information Consortium) and PsycINFO. The search was completed on 22 February 2018 and the full list of search terms is included in Table 1. A manual search of the references was also conducted to identify the grey literature and those papers not indexed in the above databases. Our own unpublished case of McKittrick-Wheelock syndrome was added to the data.

A paper was included if it contained the report of one or more cases of a colorectal tumour with associated renal dysfunction and/or electrolyte disturbance. All languages and all formats of publication such as letters, conference abstracts and published case reports were considered. The process for assessment and exclusion is summarised in Figure 1.

Every full text was reviewed by the primary author and information extracted about the cases presented. Not all the information was included for every case. No assumptions were made about missing data except that if a patient was not reported to have died, they were assumed to have survived as it was felt that this information would not have been omitted if the patient had died.

Non-English language papers were translated by a variety of sources: medical colleagues, lay native language speakers or Google Translate ${ }^{\mathrm{TM}}$. Although literal translation was poor via this last method, it was sufficient to identify the specific pieces of information required. Data analysis

Table 1 Search terms
1. ((fluid* OR electrolyte*) AND (imbalance OR loss OR
abnormal* OR deplet* OR disturb* OR secret*)).ti,ab
2. (Hypokal* OR Hypona*).ti,ab
3. (1 OR 2)
4. (colorectal OR rectal* OR rectum* OR recto*).ti,ab
5. (villous OR tubulo-villous OR tubular).ti,ab
6. (3 AND 4)
7. (Mckittrick OR Wheelock).ti,ab
8. (6 OR 7)

was performed with $\mathrm{R}$ statistical software (version 3.3.3; R Foundation for Statistical Computing, Vienna, Austria; https://www.r-project.org/), which was used to produce summary statistics and investigate several possible trends or correlations, mostly visually through scatterplots and boxplots.

\section{Results}

The literature search along with the manual search of the references identified 209 papers reporting on 257 patients with electrolyte depletion syndrome. This is nearly twice as many as those in any previous literature review of the condition.

Table 2 shows the presenting symptoms and characteristics. Almost all patients presented with diarrhoea, invariably described as watery or mucous. The median frequency of stools was 10 per 24 hours $(n=88)$ (Table 3) and there was a higher stool frequency for patients who died (median 12.5, $n=8$ ) than for those who survived (median 10, $n=80$ ). Nausea and vomiting and decreased Glasgow coma scale score were also very common presenting symptoms, most likely reflecting the severe renal and electrolyte disturbances. Most of the patients presented in extremis. The mean blood results are shown in Table 4.

An interesting feature of McKittrick-Wheelock syndrome is the very long duration of symptoms (Table 5) and multiple hospital admissions. The median symptom duration was 24 months $(n=182)$ and 47 patients had more than 1 admission reported. Both the median duration of symptoms and the median number of admissions were higher in patients who died (60 months $[n=21]$ and $3[n=5]$ respectively) than in those who survived (18 months $[n=161]$ and $2[n=43]$ respectively).

The tumours are usually large and low in the rectum (Table 6), making them potentially challenging to remove surgically. The majority of the tumours $(99.2 \%, n=238)$ were distal to the splenic flexure, and the main operations used historically were abdominoperineal resection and anterior resection (Table 7 ). Both are major, life changing operations involving a high level of morbidity and mortality.

We also identified a raised white cell count on admission (median $14.6 \times 10^{9} / 1, n=73$ ), which has not previously been identified as a feature of McKittrick-Wheelock syndrome. Similarly, significant weight loss was reported in some patients (61 patients reported weight loss; mean loss $10.4 \mathrm{~kg}$ in the 38 patients who had the weight lost recorded). There is some association between weight loss and malignant histology but (as with the raised white cell count) the gaps in the data make it impossible to robustly calculate statistical significance.

\section{Discussion}

Given that our literature review identified 257 cases, the syndrome of electrolyte and fluid depletion due to colorectal tumours may not be as rare as suggested previously. Unfortunately, the incidence cannot be estimated from our 

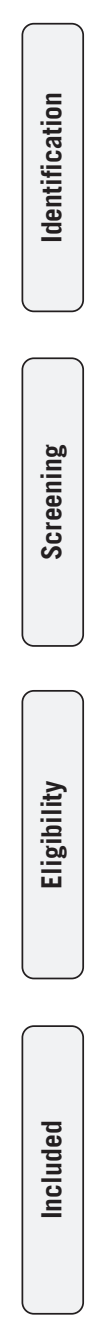

Records identified through database search $(n=328)$
Additional records identified by hand search of references

$$
(n=106)
$$

+1 unpublished case report from the authors

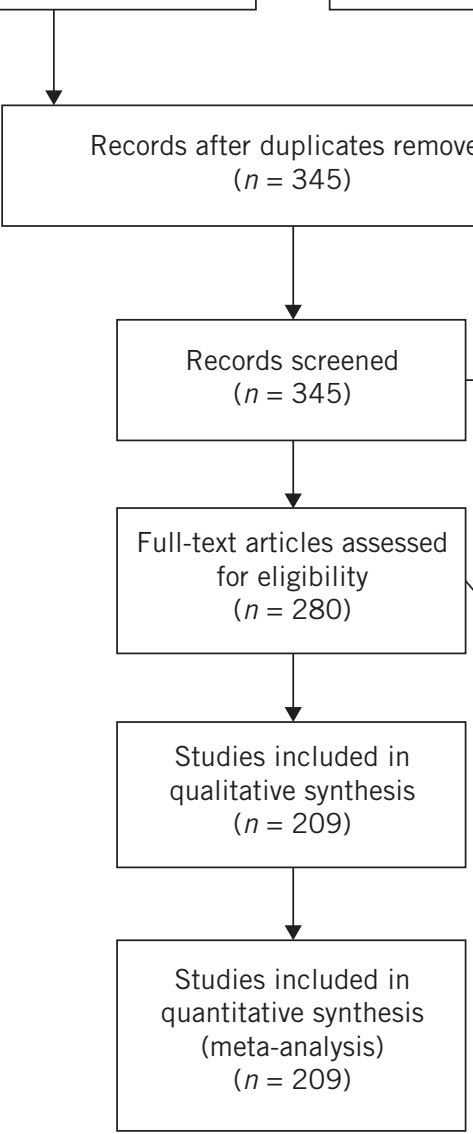

Records excluded as irrelevant $(n=65)$

antitative synthesis

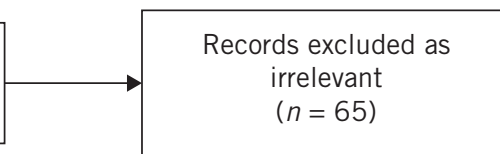

Figure 1 Flowchart of studies included in review

data. Cases may have been overlooked owing to the variety of terms used to report the condition (McKittrick-Wheelock syndrome, electrolyte depletion syndrome and secretory villous adenoma). It may be helpful to unify future reports of this condition under the term electrolyte depletion syndrome rather than using the eponymous term McKittrick-Wheelock syndrome.

Whatever terminology is used, this condition remains clinically interesting. In 1969 Langeron et al described three stages of electrolyte depletion syndrome: a long latent phase, a short deterioration phase and a decompensation phase. ${ }^{13}$ This process is demonstrated by the case reports reviewed. The average duration of symptoms reported across the papers was 24 months $(n=182)$. Diarrhoea was generally the most longstanding symptom. There was usually then an increase in diarrhoea frequency associated with other common symptoms (nausea and vomiting, weakness, altered Glasgow coma scale score, syncope and anorexia). The subsequent decompensation phase resulted in patients being admitted who were critically unwell with severe hyponatraemia, hypokalaemia and/or acute kidney injury.

The delay in diagnosis due to the long latent phase is already being addressed. In the UK, patients with persistent diarrhoea are now routinely referred for investigation under the two-week wait rule. Our data show a trend for decreasing duration of symptoms over the decades (Table 5) although the median duration of symptoms since screening was introduced in the year 2000 was still 11 months $(n=101)$. It would be beneficial for clinicians who identify large tumours at endoscopy to ensure that recent urea and electrolytes have been checked to minimise delays in diagnosis, and to avoid patients reaching the decompensation phase.

A further delay to diagnosis is that at the point of decompensation, the patients are often managed by general 


\begin{tabular}{|c|c|c|c|}
\hline Male-to-female ratio $(n=255)$ & \multicolumn{3}{|c|}{$117: 138$} \\
\hline Age $(n=254)$ & \multicolumn{3}{|c|}{ Median 69 years (range: $22-101$ years) } \\
\hline Duration of symptoms ( $n=182$ ) & \multicolumn{3}{|c|}{ Median 24 months (range: $0.1-228$ months) } \\
\hline Presenting symptoms ( $n=257$ ) & Yes & No & Not recorded \\
\hline Diarrhoea & $92.2 \%$ & $1.6 \%$ & $6.2 \%$ \\
\hline Mass on digital rectal examination & $42.0 \%$ & $14.4 \%$ & $43.6 \%$ \\
\hline Nausea and/or vomiting & $40.1 \%$ & & $59.9 \%$ \\
\hline Weakness and/or fatigue & $40.1 \%$ & & $59.9 \%$ \\
\hline Weight loss & $23.7 \%$ & $4.3 \%$ & $72.0 \%$ \\
\hline Altered Glasgow coma scale score & $19.8 \%$ & & $80.2 \%$ \\
\hline Syncope and/or dizziness & $14.8 \%$ & & $85.2 \%$ \\
\hline Anorexia & $14.0 \%$ & & $86.0 \%$ \\
\hline Rectal bleeding & $12.5 \%$ & & $87.5 \%$ \\
\hline \multirow[t]{2}{*}{ Electrocardiography changes $(n=257)$} & Yes & No & Not recorded \\
\hline & $25.3 \%$ & $2.3 \%$ & $72.4 \%$ \\
\hline
\end{tabular}

Table 3 Rectal losses

\begin{tabular}{|c|c|c|c|}
\hline & & & Normal losses \\
\hline \multicolumn{2}{|c|}{ Frequency of stools per $24 \mathrm{hrs}(n=88)$} & Median 10 (range: 2-20) & \\
\hline \multicolumn{2}{|c|}{ Volume of losses per 24 hrs $(n=72)$} & Median 1.95I (range: 0.1-5I) & 0.151 \\
\hline \multirow[t]{3}{*}{ Electrolyte losses in stool } & Sodium ( $n=68)$ & Mean $119.2 \mathrm{mmol} / \mathrm{l}$ (range: $14-250 \mathrm{mmol} / \mathrm{l}$ ) & $<30 \mathrm{mmol} / \mathrm{l}$ \\
\hline & Potassium ( $n=73$ ) & Mean 36.0mmol/I (range: $2.5-191 \mathrm{mmol} / \mathrm{l})$ & $55-75 \mathrm{mmol} / \mathrm{l}$ \\
\hline & Chloride $(n=53)$ & Mean $119.0 \mathrm{mmol} / \mathrm{l}$ (range: $41-302 \mathrm{mmol} / \mathrm{l})$ & $<30 \mathrm{mmol} / \mathrm{l}$ \\
\hline
\end{tabular}

Table 4 Admission blood test results

\begin{tabular}{|c|c|c|}
\hline Blood test & Median (range) & Normal range \\
\hline Sodium ( $n=206)$ & $122 \mathrm{mmol} / /(93-151 \mathrm{mmol} /)$ & $133-146 \mathrm{mmol} / \mathrm{l}$ \\
\hline Potassium ( $n=220$ ) & $2.7 \mathrm{mmol} / \mathrm{l}(1.3-6 \mathrm{mmol} / \mathrm{l})$ & $3.5-5.3 \mathrm{mmol} / \mathrm{l}$ \\
\hline Chloride $(n=148)$ & $75 \mathrm{mmol} / \mathrm{l}(41-115.2 \mathrm{mmol} / \mathrm{l})$ & $95-108 \mathrm{mmol} / \mathrm{l}$ \\
\hline Urea $(n=161)$ & $45 \mathrm{mmol} / \mathrm{l}(2.8-178 \mathrm{mmol} / \mathrm{l})$ & $2.5-7.8 \mathrm{mmol} / \mathrm{l}$ \\
\hline Creatinine ( $n=107$ ) & $335.9 \mu \mathrm{mol} / \mathrm{l}(61.9-1,440 \mu \mathrm{mol} / \mathrm{l})$ & $\begin{array}{l}\text { Men } 59-104 \mu \mathrm{mol} / \mathrm{l} \\
\text { Women } 45-84 \mu \mathrm{mol} / / \mathrm{I}\end{array}$ \\
\hline White cell count $(n=73)$ & $14.6 \times 10^{9} / \mid\left(6.8-32.0 \times 10^{9} / I\right)$ & $4-11 \times 10^{9} / 1$ \\
\hline
\end{tabular}

medical or specialist renal teams and other (more common) diagnoses are usually considered first, including gastroenteritis, diabetic ketoacidosis, hyperaldosteronism, diuretics and colitis. ${ }^{14}$ The first step to improving management of these patients is therefore to raise awareness of electrolyte depletion syndrome for its inclusion among the initial differential diagnoses.

Another cause for delay that has previously been reported is that digital rectal examination can miss even very large tumours owing to their soft, mucin covered 
Table 5 Duration of symptoms prior to presentation and diagnosis over the decades

\begin{tabular}{|c|c|c|c|c|c|c|c|c|c|}
\hline & $1940 s$ & $1950 \mathrm{~s}$ & $1960 \mathrm{~s}$ & 1970 s & $1980 \mathrm{~s}$ & $1990 \mathrm{~s}$ & 2000 s & $2010 s$ & Total \\
\hline Number of cases & 1 & 17 & 57 & 38 & 15 & 28 & 34 & 67 & 257 \\
\hline $\begin{array}{l}\text { Median duration of } \\
\text { symptoms }\end{array}$ & 6 months & 60 months & 42 months & 48 months & 60 months & 12 months & 12 months & 9 months & $\begin{array}{l}24 \text { months } \\
(n=182)\end{array}$ \\
\hline
\end{tabular}

\begin{tabular}{|c|c|c|}
\hline \multicolumn{3}{|l|}{ Location ( $n=238)$} \\
\hline Rectum & \multicolumn{2}{|l|}{$60.5 \%$} \\
\hline Rectosigmoid & \multicolumn{2}{|l|}{$32.4 \%$} \\
\hline Sigmoid & \multicolumn{2}{|l|}{$2.9 \%$} \\
\hline Other & \multicolumn{2}{|l|}{$1.3 \%$} \\
\hline Distance from anal margin $(n=134)$ & \multicolumn{2}{|l|}{$\begin{array}{l}\text { Median } 5 \mathrm{~cm} \\
\text { (range: } 0-18 \mathrm{~cm} \text { ) }\end{array}$} \\
\hline Size $(n=178)$ & \multicolumn{2}{|l|}{$\begin{array}{l}\text { Median } 12 \mathrm{~cm} \\
\text { (range: } 2-31 \mathrm{~cm} \text { ) }\end{array}$} \\
\hline$\%$ luminal circumference $(n=104)$ & \multicolumn{2}{|l|}{ Median 100\% } \\
\hline Dysplasia present ( $n=103)$ & Yes & Not recorded \\
\hline & $26.8 \% 13.2 \%$ & $59.9 \%$ \\
\hline
\end{tabular}

\begin{tabular}{|c|c|}
\hline Time from admission to surgery $(n=74)$ & $\begin{array}{l}\text { Median } 27.2 \text { days } \\
\text { (range: } 2-132 \text { days) }\end{array}$ \\
\hline \multicolumn{2}{|l|}{ Operation $(n=257)^{*}$} \\
\hline Anterior resection & $30.4 \%$ \\
\hline Abdominoperineal resection & $27.2 \%$ \\
\hline $\begin{array}{l}\text { Sigmoid colectomy/Hartmann's } \\
\text { procedure }\end{array}$ & $7.0 \%$ \\
\hline Transanal resection & $5.8 \%$ \\
\hline Endoscopic resection & $5.4 \%$ \\
\hline Stoma & $3.1 \%$ \\
\hline Other & $14.0 \%$ \\
\hline None & $10.1 \%$ \\
\hline Not known & $0.8 \%$ \\
\hline Deaths $(n=257)$ & $10.5 \%$ \\
\hline
\end{tabular}

surface, often described as 'velvet like'. ${ }^{15,16}$ This is not backed up by the case reports we reviewed, however. Of the 72 patients with a tumour within $8 \mathrm{~cm}$ of the anal margin and who had a rectal examination recorded, $88.9 \%$ had a mass that was palpable.
To our knowledge, this is the most comprehensive review of the published cases of McKittrick-Wheelock syndrome. Despite this, there are multiple gaps throughout our dataset as the information came solely from case reports so statistical analysis was not possible. The underlying pathophysiology that causes the depletion syndrome in certain colorectal tumours has also not been explored. In addition, it would be interesting to investigate what precipitates the sudden decompensation. A significant proportion $(40.1 \%)$ of patients present with nausea and/or vomiting. It is not clear whether these are symptoms of the renal failure or whether another process causes nausea and vomiting, which then overwhelms the patient's normal compensatory mechanisms. A raised white cell count was reported in $28.4 \%$ of cases and weight loss in $23.7 \%$. This has not been highlighted in other reviews and the clinical significance of these findings is uncertain.

The treatment options below are those discussed in the published case reports of McKittrick-Wheelock syndrome. The current national guidelines recommend that all large colorectal polyps are discussed at a multidisciplinary team (MDT) meeting. ${ }^{17}$

\section{No intervention}

According to Emrich and Niemayer, the mortality rate for secretory villous adenomas without treatment would be $100 \% .{ }^{14}$ Among the cases in our literature review, there were 26 patients who had no surgery, of whom 16 $(61.5 \%)$ died, and 229 who had surgery, of whom 12 $(5.2 \%)$ died.

\section{Medical management}

Indomethacin $^{18}$ and octreotide ${ }^{19}$ have been used to reduce fluid losses while awaiting definitive surgery or as an alternative to surgical intervention. Among the cases in our review, there were eight patients who died before definitive treatment was initiated. Of the remaining 18 patients who had no surgery, 10 underwent medical management and of these, $1(10.0 \%)$ died. The remaining eight patients had no medical therapy beyond fluid and electrolyte replacement, and seven (87.5\%) died. Nevertheless, the numbers are very small, and previous papers have suggested that pharmacological treatments add no benefit beyond appropriate fluid and electrolyte replacement. ${ }^{20}$ Based our findings, medical management would definitely be worth considering if a patient is not fit for surgery or chooses not to undergo surgical intervention. 


\section{Defunctioning stoma}

Eight patients had a defunctioning stoma as their primary operation but this failed to control the rectal losses in any of these patients. One patient died while awaiting definitive resection so this option is not recommended.

\section{Traditional resectional surgery}

The majority $(64.8 \%)$ of patients underwent anterior resection, abdominoperineal resection, Hartmann's procedure or sigmoid colectomy. These all resulted in full resolution of symptoms and electrolyte abnormalities, and are likely to still be the operations of choice. Ultralow anterior resection and abdominoperineal resection remain major operations, however, with a substantial risk of sepsis, prolonged recovery, colostomy and potential incontinence in the future. Increasingly, we are presented with patients who are older and frailer. For these patients, the prospect of major (potentially life threatening) surgery is not an attractive option.

\section{Minimally invasive options}

Fourteen patients underwent endoscopic resection of the tumours. Two $(14.3 \%)$ of these patients subsequently still required definitive surgical resection and a further two $(14.3 \%)$ required multiple procedures to remove the tumour. Mois et al reported that brachytherapy and endoscopic resection have poor results and high recurrence rates in these tumours. ${ }^{11}$

Fifteen patients underwent transanal excision with successful results; only one was reported as needing repeat procedures. The average size of these tumours means that transanal surgery has a high risk of morbidity and local recurrence. ${ }^{21}$

The numbers of patients who had undergone the more minimally invasive treatment options so far were small as the majority of the case reports were published prior to the year 2000. Current practice and guidelines have moved towards specialist management of large polyps because of their complexity and high rates of malignancy; data from the National Health Service bowel cancer screening programme has shown that $40 \%$ of flat polyps of $>2 \mathrm{~cm}$ in size may contain an adenocarcinoma. ${ }^{17}$ The current recommendations are that these polyps should be removed en bloc for full histopathological evaluation. Endoscopic resection for complex anal polyps is increasingly used and newer, minimally invasive transanal surgical techniques have shown promising results in tumours higher up the rectum. ${ }^{22}$ Both approaches can be performed as day-case procedures, making them attractive options for patients regardless of age.

\section{Key recommendations}

Based on the findings of our literature review, we make the following recommendations for management of McKittrick-Wheelock syndrome:

$>$ Aggressive fluid resuscitation: It is necessary to involve the intensive care team for aggressive replacement of fluid and electrolytes. It is important to measure rectal losses (both volume and electrolytes) as these are often underestimated when managing fluid replacement. $^{23}$

$>\quad$ Early flexible sigmoidoscopy: Choi et al believe that a complete colonoscopy is mandatory in all patients. ${ }^{10}$ Given the location of the tumours, we believe that flexible sigmoidoscopy will permit diagnosis in $99 \%$ of cases. The requirement for bowel preparation in a patient with severe electrolyte disturbance or renal dysfunction is likely to add delay to diagnosis. Full colonic imaging will be required at some point but can safely be delayed in the first instance.

$>\quad$ CT of the abdomen and pelvis: Forty-nine patients had computed tomography (CT) as part of their preoperative workup; the tumour was identified in all of these cases. Two patients presented with metastatic disease and one with an incidental finding of a congenitally absent kidney, which suggests CT is a useful part of the preoperative investigations once renal function has recovered. Other imaging modalities have been used more widely in recent years to look for evidence of local spread, including endoanal ultrasonography $(n=14)$ and magnetic resonance imaging $(n=14)$, and these would be requested at the discretion of the colorectal MDT.

> Colorectal MDT discussion: All large polyps should be discussed routinely by the MDT. There is a high rate of malignancy in these tumours. An adenocarcinoma was identified in the resected specimen in 47 patients $(18.6 \%)$. Furthermore, the tumours are often very large and low, and benefit from specialist input, as discussed in the treatment options listed above.

$>$ Operate during the index admission: Forty-seven patients $(18.6 \%)$ were reported to have more than one acute admission with the same condition prior to definitive management. Our own experience of managing a patient with electrolyte depletion syndrome is reflected in many of the case reports. The symptoms, electrolyte abnormalities and acute kidney injury are fully correctable by fluid resuscitation but a definitive diagnosis is not found or left to ongoing outpatient management, meaning these patients are at high risk of repeated admissions.

\section{Conclusions}

Electrolyte depletion syndrome is a clinically significant condition as patients often present critically unwell and we believe all clinicians should be aware of it. This is the largest literature review on this subject to date, reporting 257 cases (although the true incidence is unknown). Based on our findings, we have outlined key recommendations and discussed available treatment options for the management of these patients. 


\section{References}

1. McKittrick LS, Wheelock FC. Carcinoma of the Colon. Springfield, IL: Charles C Thomas; 1954. p61.

2. Garis RW. Prerenal uremia due to papilloma of rectum. Ann Intern Med 1941; 15: 916-926.

3. Malik S, Mallick B, Mattar K et al. Malignant McKittrick-Wheelock syndrome as a cause of acute kidney injury and hypokalemia: report of a case and review of literature. Intractable Rare Dis Res 2016; 5: 218-221.

4. Nicholson P, Naugler C. McKittrick-Wheelock syndrome may represent the extreme of a normally distributed continuum of secretory activity in colorectal villous adenomas. Clin Chim Acta 2014; 436: 9-10.

5. Roy $A D$, Ellis H. Potassium-secreting tumours of the large intestine. Lancet 1959; 1: 759-760.

6. Caliskan C, Makay O, Firat 0 et al. McKittrick-Wheelock syndrome: is it really rare? Am J Emerg Med 2010; 28: 105-106.

7. Georgeac C, Serra-Maudet V, Bruant P et al. Hypersecreting villous rectosigmoid tumors. Apropos of 14 cases. J Chir 1994; 131: 121-123.

8. Bozkurt N, Omer Özütemiz A, Akgün E et al. Adenoma with rectal villous diarrhoea and severe hypokalaemia (McKittrick-Wheelock syndrome). Br J Hosp Med 2013; 74: 648-649.

9. Khalife M, Eloubeidi MA, Hosn MA. McKittrick-Wheelock syndrome presenting with dermatomyositis and rectal prolapse. Clin Exp Gastroenterol 2013; 6: 85-89.

10. Choi WH, Ryuk J, Kim HJ et al. A case of giant rectal villous tumor with severe fluid-electrolyte imbalance treated by laparoscopic low anterior resection. J Korean Surg Soc 2012; 82: 325-329.

11. Mois El, Graur F, Sechel R, Al-Hajjar N. McKittrick-Wheelock syndrome: a rare case report of acute renal failure. Clujul Med 2016; 89: 301-303.

12. Moher D, Liberati A, Tetzlaff J, Altman DG. Preferred reporting items for systematic reviews and meta-analyses: the PRISMA statement. PLoS Med 2009; 6(7): e1000097.
13. Langeron P, Prévost AG, Boudailliez C. Rectosigmoid villous tumors with hydroelectrolytic disorders. J Sci Med Lille 1969; 87: 5-23.

14. Emrich J, Niemeyer $C$. The secreting villous adenoma as a rare cause of acute renal failure. Med Klin 2002; 97: 619-623.

15. Ashour N, Qassem JA, Al-Tourah W. Villous adenoma depletion syndrome: case report. Kuwait Med J 2007; 39: 358-360.

16. Tuță LA, Boșoteanu M, Deacu M, Dumitru E. McKittrick-Wheelock syndrome: a rare etiology of acute renal failure associated to well-differentiated adenocarcinoma (G1) arising within a villous adenoma. Rom J Morphol Embryol 2011; 52(3 Supple): 1,1153-1,156.

17. Rutter MD, Chattree A, Barbour JA et al. British Society of Gastroenterology/ Association of Coloproctologists of Great Britain and Ireland guidelines for the management of large non-pedunculated colorectal polyps. Gut 2015; 64: $1,847-1,873$.

18. Fernández-López F, Paredes-Cotore JP. McKittrick-Wheelock syndrome prolapsed giant villous adenoma of the rectum. Rev Esp Enferm Dig 2013; 105: 309-310.

19. Nakhla SG, Murakami TT, Sundararajan S. Poorly differentiated neuroendocrine tumor of the rectum coexistent with giant rectal villous adenoma presenting as McKittrick-Wheelock syndrome. Case Rep Oncol Med 2015; 242760.

20. Chen YH, Kang JC, Lai HJ. Rectal villous adenoma with McKittrick-Wheelock syndrome: report of a rare case. Visc Med 2013; 29: 55-58.

21. Targarona EM, Hernandez PM, Balague C et al. McKittrick-Wheelock syndrome treated by laparoscopy: report of 3 cases. Surg Laparosc Endosc Percutan Tech 2008; 18: 536-538.

22. Sumrien H, Dadnam C, Hewitt J, McCarthy K. Feasibility of transanal minimally invasive surgery (TAMIS) for rectal tumours and its impact on quality of life the Bristol series. Anticancer Res 2016; 36: 2,005-2,009.

23. Schrock LG, Polk HC. Rectal villous adenoma producing hypokalemia. Am Surg 1974; 40: 54-59. 